\title{
When do interfaces become important for failure?
}

\author{
S.J. Fensin ${ }^{1}$, a, E.K. Walker ${ }^{1,2}$, E.K. Cerreta ${ }^{1}$, and G.T. Gray III ${ }^{1}$ \\ ${ }^{1}$ Los Alamos National Laboratory, Los Alamos, NM 87544, USA \\ ${ }^{2}$ School of Materials Engineering, Purdue University, West Lafayette, IN 47907, USA
}

\begin{abstract}
Previous experimental research has shown that microstructural features such as interfaces, inclusions, vacancies and heterogeneities can all act as void nucleation sites. However, it is not well understood how important these interfaces are to the damage evolution as a function of the surrounding parent materials. In this work, we present results on three different materials: 1) $\mathrm{Cu}, 2) \mathrm{Cu}-10 \mathrm{wt} \% \mathrm{Ag}$, and 3) $\mathrm{Cu}-15 \mathrm{wt} \% \mathrm{Nb}$ examined to probe the influence of bi-metal interfaces on void nucleation and evolution. These materials were chosen due to the differences in the stacking fault energy between the two phases. The initial results suggest that when there are significant differences between the bulk properties (for example: stacking fault energy and melting temperature etc) the type of interface between the two parent materials does not influence the damage process. Rather, it is the "weaker" material that dictates the dynamic spall strength of the material.
\end{abstract}

\section{Introduction}

Multi-phase alloys are one class of materials that are widely utilized in modern engineering applications. The two-phase nature of such engineering alloys is balanced to enhance the best properties of each phase. For example, strength from one and ductility from the other. In this work, we consider two $\mathrm{Cu}$ matrices with a small amount of a softer $(\mathrm{Ag})$ and a harder second phase $(\mathrm{Nb})$, respectively. The aim of this study is to not only understand the role of a second phase in void nucleation and growth but also to investigate conditions (soft/soft vs. soft/hard) under which interfaces between the two phases are not important to the damage evolution and failure process. In addition, we are also interested in studying the mechanisms and how they change when the bi-metal interface changes from $\mathrm{FCC} / \mathrm{FCC}$ to $\mathrm{FCC} / \mathrm{BCC}$.

In the past, extensive research has focused on understanding the dynamic fracture response of both metals and alloys, especially in cases where the second phase additions are stiffer than the primary metallic phase. In the case of single-phase ductile materials, it is widely accepted that microstructure affects the response of a material to dynamic loading [1-7]. For example, experiments by Kanel et al. [8] on high-purity copper indicate that the onset stress for dynamic fracture (i.e. spall strength) of single-crystal copper is two to three times higher than that of polycrystalline copper. This observation suggests that the threshold stress for void nucleation at a grain boundary (GB) might be significantly lower than for nucleation at other defects like dislocation cell walls [8]. Recent experiments by Escobedo et al. [9] on polycrystalline $\mathrm{Cu}$ additionally demonstrate that certain special $(\Sigma 3)$ boundaries are more resistant to void nucleation during dynamic loading. This work also corroborates the experimental results of Wayne et al.

${ }^{a}$ Corresponding author: saryuj@lanl.gov
[10] on $\mathrm{Cu}$, which shows that boundaries with certain misorientations are preferred locations for intergranular damage. These results collectively suggest that the types of grain boundaries in a sample can strongly influence the amount and location of damage in a material during dynamic loading. However, less is understood about this effect under conditions of two-phase boundaries or at bimetallic interfaces.

In contrast, work by Minich et al. [5] on two phase materials like single crystal copper with $\mathrm{SiO}_{2}$ inclusions shows that the presence of small, hard $\mathrm{SiO}_{2}$ precipitates lowers the stress required to nucleate voids in this material as compared to that for pure $\mathrm{Cu}$. Similarly, work by Christy et al. [11] that studies inclusions present at a grain boundary in $\mathrm{Cu}$, reveals that voids prefer to nucleate at these inclusions along the grain boundaries. Gray et al. [12] show an interface dependence of this phenomena based on the response of aluminum with alumina inclusions and within a $\mathrm{Cu} / \mathrm{Nb}$ material. The spall strength of the $\mathrm{Al} / \mathrm{Al}_{2} \mathrm{O}_{3}$ system is found to be lower than that of pure aluminum and is highly dependent on the volume fraction of inclusions and their specific particle morphology. On the other hand, the spall strength of a $\mathrm{Cu} / \mathrm{Nb}$ system remains unchanged by the presence of 15 vol \% $\mathrm{Nb}$ particles embedded in the $\mathrm{Cu}$ matrix in comparison to high purity copper. Although these and other experimental observations show that the presence of a second phase can impact the spall strength of a material, the specific mechanisms behind damage nucleation and its evolution in these two-phase materials remain poorly understood.

To thoroughly understand the role of bi-metal or metal/inclusion interfaces on damage behavior, we have conducted a series of systematic plate impact experiments on $\mathrm{Cu}-10 \mathrm{wt} \% \mathrm{Ag}$ and $\mathrm{Cu}-15 \mathrm{wt} \% \mathrm{Nb}$. These results have been compared with similar experiments performed on high-purity $\mathrm{Cu}$. The remainder of this paper is organized as 


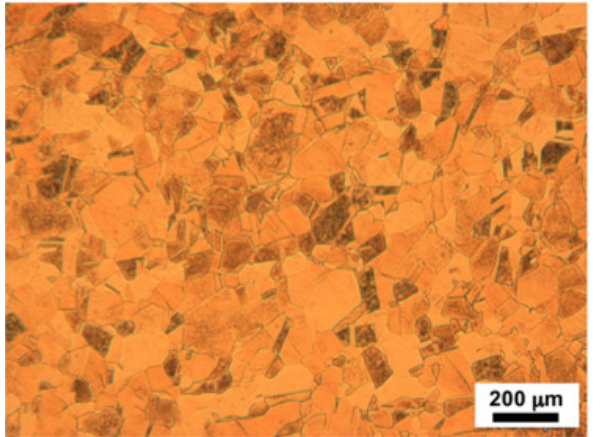

Figure 1. Optical image showing the equiaxed grain structure of the annealed high purity $\mathrm{Cu}$.

follows. The next section discusses the details of the plateimpact experiments and resulting analysis undertaken in this study. The results and conclusions are presented in Sects. III and IV, respectively.

\section{Experimental methodology}

In this section, we outline the materials, as well as experimental and analytical approaches utilized in this investigation.

\subsection{Initial material characterization}

The target materials were prepared from 1) high purity annealed $\mathrm{Cu}, 2$ ) annealed $\mathrm{Cu}-\mathrm{Ag}$ alloy with $10 \mathrm{wt} \% \mathrm{Ag}$ and 3) $\mathrm{Cu}-\mathrm{Nb}$ alloy with $15 \mathrm{wt} \% \mathrm{Nb}$. It is important to note that the $\mathrm{CuNb}$ was not heat treated in this case.

The microstructure of the annealed specimens was examined with optical microscopy using a Zeiss microscope. It was difficult to obtain EBSD data for the $\mathrm{CuAg}$ and $\mathrm{CuNb}$ alloys due to their two-phase nature. Standard metallographic techniques were used to prepare samples for inspection. For all samples, a final polish of $1 \mu \mathrm{m} \mathrm{Al}{ }_{2} \mathrm{O}_{3}$ was followed by vibratory polishing using a solution of $0.04 \mu \mathrm{m}$ colloidal silica. The $\mathrm{Cu}$ samples were lightly etched using a solution of $\mathrm{FeCl}_{3}$ and $\mathrm{HCl}$ whereas the $\mathrm{CuAg}$ and $\mathrm{CuNb}$ samples were not etched.

Figure 1 shows an optical image for the high-purity $\mathrm{Cu}$. This micrograph shows that $\mathrm{Cu}$ has equiaxed grains with an average grain size of $60 \mu \mathrm{m}$, whereas Fig. 2 shows the optical micrographs for $\mathrm{CuAg}$ and $\mathrm{CuNb}$. In contrast to pure $\mathrm{Cu}, \mathrm{CuAg}$ has a eutectic microstructure with a small effective grain size (typical for eutectic materials) and $\mathrm{Nb}$ is present in precipitate form in the $\mathrm{Cu}$ matrix in the $\mathrm{CuNb}$ material. Even though the initial microstructures for these materials are different, phenomenological comparison of the locations for void nucleation is made to determine the role of a second phase in void nucleation and growth processes.

\subsection{Plate impact experiments}

A plate impact experiment was conducted using a 80-mm bore gas launcher and soft-recovery techniques as shown using the configuration in Fig. 3 [13]. An impactor of $\mathrm{Cu}$ was accelerated using an $80 \mathrm{~mm}$ bore gas gun at a velocity of $190 \mathrm{~m} / \mathrm{s}$ and impacted onto the $\mathrm{Cu}, \mathrm{CuAg}$ and

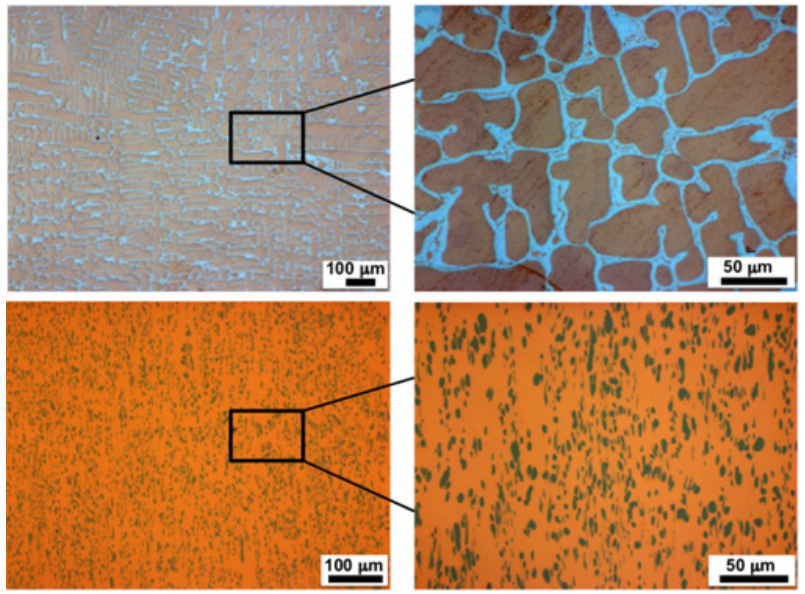

Figure 2. Optical images showing the initial microstructure of $\mathrm{Cu}-10 \% \mathrm{Ag}$ (top) and $\mathrm{Cu}-15 \% \mathrm{Nb}$ (bottom), respectively. In the top image the white regions show silver and the grey particles in the bottom image depict $\mathrm{Nb}$.

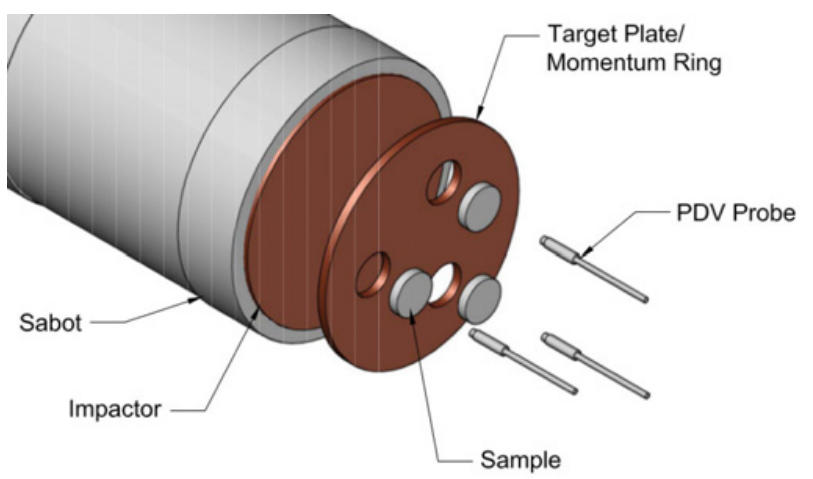

Figure 3. Experimental configuration used to produce incipient damage or complete spall in three samples simultaneously. Copper impactors were accelerated in an $80 \mathrm{~mm}$ gas gun and impacted onto the target. PDV probes were placed over the center of each sample to provide free-surface velocimetry data from each sample in each experiment.

$\mathrm{CuNb}$ targets. The impactor was roughly $1.29 \mathrm{~mm}$ thick. The target consisted: a target plate with three samples, and a momentum ring for the whole target. Targets were $2.59 \mathrm{~mm}$ thick and designed specifically such that recovery of the shocked samples was facilitated for post-mortem examination. The momentum rings were press-fit into the target plate to ensure intimate contact of all the components. For the three-sample targets, samples were machined as right, regular cylinders $12.7 \mathrm{~mm}$ in diameter. In the experiment, the impactor thickness was one-half the sample thickness to cause tensile damage to occur in the center of the sample thickness. A single momentum trapping ring made out of $\mathrm{Cu}$ surrounded the whole assembly. This was done because the sample diameters were large such that the sample had ample time to release before the edge waves came back to the sample. Placement of the samples in the target ring were set such that the shortest distance between sample edges to each other and to the edge of the target plate were equal.

Free surface velocities were measured in each experiment using Photon Doppler Velocimetry (PDV) 

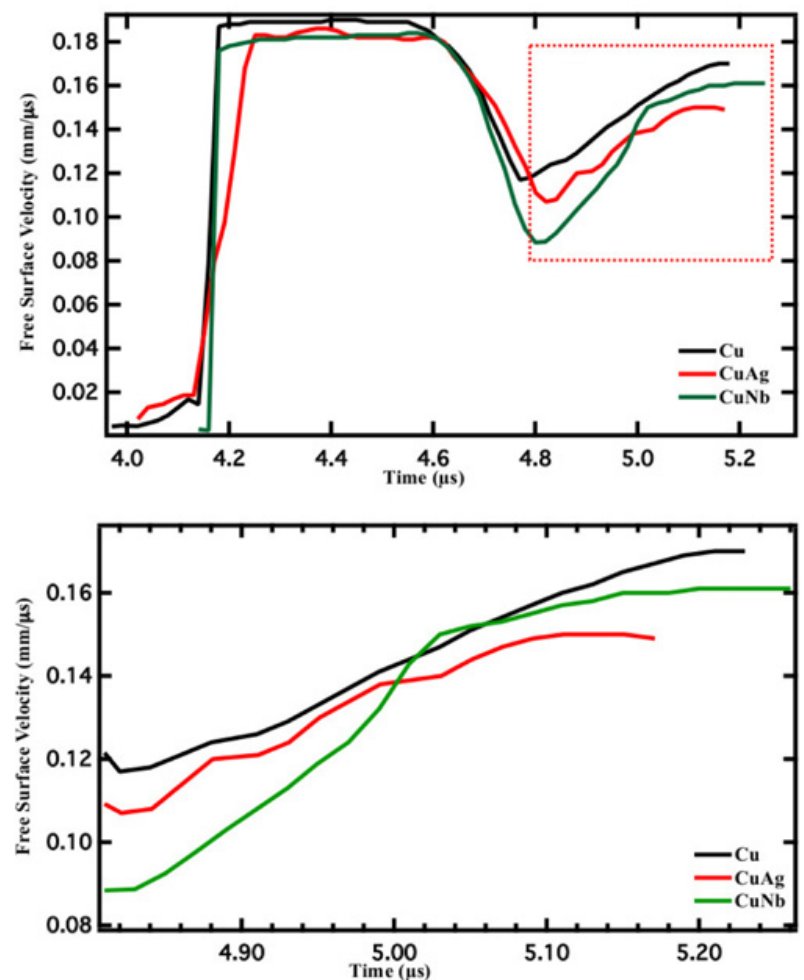

Figure 4. (Top) traces of the free surface velocity showing shock loading for $\mathrm{Cu}, \mathrm{CuAg}$ and $\mathrm{CuNb}$ experiments. (Bottom) free surface velocity rise after the minima.

$[14,15]$. Collimated probes provided by AC Photonics (Part \#: 1CL15P020LC-C01) were positioned to collect velocimetry data from the center of each sample and connected to a LANL-built 4-channel PDV system. One additional PDV probe (not shown in figure) was placed next to each target plate to measure the projectile velocity directly to an accuracy of $0.1 \%$ [15]. A single PZT trigger pin (Dynasen, Inc.) was also positioned next to each target plate with a typical standoff distance of a few millimeters to provide a trigger to the digitizer used to collect the PDV data. Following impact, all samples were "soft recovered" by decelerating them into low-density foam.

\subsection{Postimpact metallurgical characterization}

Subsequent characterization of the damage in the spalled samples included both optical microscopy. In preparation for the optical analyses, each recovered specimen was diametrically sectioned. They were subsequently mounted in an epoxy resin and prepared following standard metallographic techniques as listed above in Sect. 2.1.

\section{Results}

\subsection{Free surface velocity analysis}

Free surface velocity (FSV) profiles provide in-situ information regarding the motion of shock waves in a sample and can be used to infer the stresses and kinetics associated with void nucleation and growth. Figure 4 shows the FSV histories for the incipient spall experiments on $\mathrm{Cu}, \mathrm{CuAg}$ and $\mathrm{CuNb}$.
Table 1. Parameters used to calculate peak stress and spall strength. Parameters for $\mathrm{CuAg}$ and $\mathrm{CuNb}$ were calculated through using a weighted average of the individual parameters for each component.

\begin{tabular}{ccccccc}
\hline Experiment & $\begin{array}{c}\rho \\
\left(\mathrm{g} / \mathrm{cm}^{3}\right)\end{array}$ & $\begin{array}{c}\mathrm{C}_{B} \\
(\mathrm{~mm} / \mu \mathrm{s})\end{array}$ & $\begin{array}{c}\mathrm{C}_{L} \\
(\mathrm{~mm} / \mu \mathrm{s})\end{array}$ & $\mathrm{s}$ & $\gamma$ & $\begin{array}{c}\mathrm{h} \\
(\mathrm{mm})\end{array}$ \\
\hline $\mathrm{Cu}$ & 8.924 & 3.94 & 4.72 & 1.489 & 1.96 & 1.08 \\
\hline $\mathrm{CuAg}$ & 9.081 & 3.87 & 4.72 & 1.495 & 1.96 & 0.43 \\
\hline $\mathrm{CuNb}$ & 8.873 & 4.02 & 4.77 & 1.445 & 1.96 & 1.06 \\
\hline \hline
\end{tabular}

The wave profiles for the three materials are seen to display a number of features: 1) Lack of elastic-plastic transitions, or Hugoniot Elastic Limits (HEL's), as seen in the loading portion of the profile, 2) CuAg has a different slope in the loading part of the velocity profile. This could be related to non-uniform dissipation of energy through plasticity which is further related to the higher propensity of $\mathrm{Ag}$ to undergo extensive deformation twinning, 3) Constant responses upon the peak stress on the Hugoniot suggestive of uniform plastic deformation with all the samples, 4) Upon release all profiles exhibit a classic pullback signal and ringing, which generally is associated with spall or dynamic fracture in the sample. However, there are different magnitude of the "pull-back" signal quantified by $\triangle$ FSV suggesting different damage nucleation responses in the materials and 5) Similar slopes for the free surface velocity rise for $\mathrm{Cu}$ and $\mathrm{CuAg}$ are observed. These slopes are different from the one observed in $\mathrm{CuNb}$ which shows two different slopes in this rise region.

Due to the different composition of the materials, the peak free surface velocities are $0.187,0.182,0.182 \mathrm{~mm} / \mu \mathrm{s}$ in $\mathrm{Cu}, \mathrm{CuAg}$ and $\mathrm{CuNb}$, respectively. The corresponding average peak compressive stresses are 3.40, 3.31 and $3.35 \mathrm{GPa}$ in $\mathrm{Cu}, \mathrm{CuAg}$ and $\mathrm{CuNb}$, respectively. These values are calculated using the Mie Grüneisen equation of state with parameters listed in Table 1. Parameters for $\mathrm{CuAg}$ and $\mathrm{CuNb}$ were calculated by using a weighted average of the individual parameters for each component obtained from the LASL Hugoniot EOS database [16].

The spall strength $\left(\sigma_{\text {spall }}\right)$, which is one measure of dynamic failure stress, is calculated using the relationship proposed by Novikov [17] and the correction proposed by Kanel [18]:

$$
\sigma_{\text {spall }} \equiv \frac{1}{2} \rho_{o} C_{B}(\Delta F S V+\delta),
$$

where $\rho_{o}$ is the ambient density, $C_{B}$ is the bulk sound speed and $\triangle F S V$ is the difference in the free surface velocity from the peak state to the pull-back minima (Fig. 4). The accuracy of the spall strength calculation is improved by correcting for the $\triangle F S V$ in Eq. 1 [18]:

$$
\delta=h\left(\frac{1}{C_{B}}-\frac{1}{C_{L}}\right) * \frac{\left|\dot{u}_{1} * \dot{u}_{2}\right|}{\left|\dot{u}_{1}\right|+\dot{u}_{2}},
$$

where $\mathrm{h}$ is the thickness of the spalled region (measured from optical images), $C_{L}$ is the longitudinal sound speed, and $\dot{u}_{1}$ and $\dot{u}_{2}$ are the unloading and re-compression rates calculated as

$$
\left|\dot{u}_{1}\right|=-1 / 2 \frac{d F S V}{d t} \text { and } \dot{u}_{2}=1 / 2 \frac{d F S V}{d t},
$$


Table 2. Calculated and measured parameters from the FSV data.

\begin{tabular}{|c|c|c|c|c|c|c|}
\hline \multirow[b]{2}{*}{ Shot } & \multicolumn{3}{|c|}{ Pull back characteristics } & \multirow[b]{2}{*}{$\delta(\mathrm{mm} / \mu \mathrm{s})$} & \multirow[b]{2}{*}{ Average Spall Strength (GPa) } & \multirow[b]{2}{*}{ Corrected Spall Strength (GPa) } \\
\hline & $\Delta \mathrm{FSV}(\mathrm{mm} / \mu \mathrm{s})$ & $\dot{u}_{1}\left(\mathrm{~mm} / \mu \mathrm{s}^{2}\right)$ & $\dot{u}_{2}\left(\mathrm{~mm} / \mu \mathrm{s}^{2}\right)$ & & & \\
\hline $\mathrm{Cu}$ & 69 & 0.39 & 0.148 & 0.0052 & 1.328 & 1.333 \\
\hline $\mathrm{CuAg}$ & 74 & 0.37 & 0.155 & 0.0020 & 1.421 & 1.423 \\
\hline $\mathrm{CuNb}$ & 94 & 0.49 & 0.284 & 0.0069 & 1.806 & 1.813 \\
\hline
\end{tabular}

Here, $\frac{d F S V}{d t}$ is measured from the pullback signal as described in Ref. [19] and these values for the current experiments are listed in Table 2 . The unloading rates $\dot{u}_{1}$ are indicators of the kinetics of the tensile pulse imposed on the target. These results (Table 2) indicate that the $\mathrm{CuNb}$ experiences a faster tensile stress rate as compared to the $\mathrm{Cu}$ and $\mathrm{CuAg}$.

The corrected spall strength values calculated using Eqs. (1), (2) and (3) are listed in Table. 2. The data reveals that the spall strength of $\mathrm{Cu}$ increases with the addition of $10 \% \mathrm{Ag}$ and $15 \% \mathrm{Nb}$. Specifically, the spall strengths for $\mathrm{CuAg}$ and $\mathrm{CuNb}$ are 1.42 and $1.81 \mathrm{GPa}$, respectively. These values are $6 \%$ and $26 \%$ higher than the average spall strength for $\mathrm{Cu}$. The slight increase in the spall strength of $\mathrm{CuAg}$ could be due to second phase hardening (not precipitate hardening) especially because in general silver has a slightly higher tensile strength in comparison to $\mathrm{Cu}$ [20]. In addition, the effective grain size in $\mathrm{CuAg}$ is much lower than $\mathrm{Cu}$ due to its eutectic microstructure and as such can increase the spall strength of the material. In contrast, increase in the spall strength of $\mathrm{CuNb}$ is related to precipitation hardening since $\mathrm{Nb}$ is dispersed through the matrix in the form of fine precipitate particles (Refer Fig. 2). Also, $\mathrm{Nb}$ is much harder than both $\mathrm{Cu}$ and $\mathrm{Ag}$ and is an efficient barrier to dislocation motion. In general, the microstructures of these three materials differ to the extent that it would not be fair to do a one-to-one quantitative comparison. Nonetheless, the trends in spall strengths are reasonable.

In addition, differences are also observed in the rate at which the free surface velocity rises beyond the pull-back signal minima between the three samples. Specifically, the rate of increase is similar for $\mathrm{Cu}$ and $\mathrm{CuAg}\left(0.148\right.$ and $\left.0.155 \mathrm{~mm} / \mu \mathrm{s}^{2}\right)$ but is $23 \%$ higher in $\mathrm{CuNb}\left(0.194 \mathrm{~mm} / \mu \mathrm{s}^{2}\right)$. In fact, the rise rate of $\mathrm{CuNb}$ can be divided into two parts; the first part rises faster $\left(0.284 \mathrm{~mm} / \mu \mathrm{s}^{2}\right)$ and the second part is much flatter $\left(0.054 \mathrm{~mm} / \mu \mathrm{s}^{2}\right)$. This bi-linear pull-back slope in $\mathrm{CuNb}$ is perhaps suggestive of differing energy partitioning during nucleation and growth of damage as compared to $\mathrm{Cu}$ and $\mathrm{CuAg}$ which display a linear "pull-back" signal.

\subsection{Post-impact metallurgical examination}

Even though the in-situ, FSV measurements provide insight into the stress history of the dynamically loaded materials, these continuum level measurements can only provide limited information regarding the specific details of the operative, internal damage evolution within a material. For this reason, metallographic characterization of the incipiently spalled samples was performed to gain insight into the relationship of damage evolution and

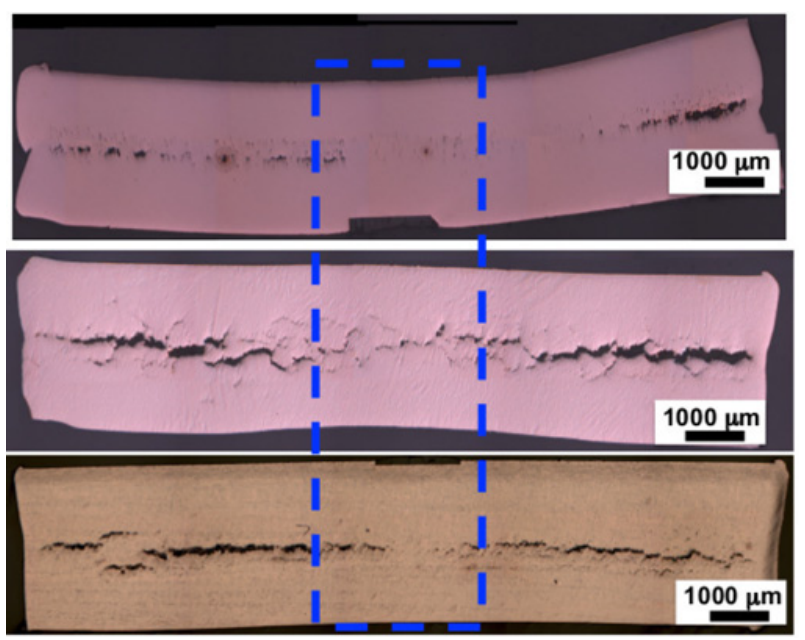

Figure 5. Optical micrographs of spalled high purity $\mathrm{Cu}$, $\mathrm{Cu}-10 \% \mathrm{Ag}$ and $\mathrm{Cu}-15 \% \mathrm{Nb}$ respectively. The spall plane is approximately located in the center of the samples except in the case of $\mathrm{CuPb}$.

microstructure as a function of material and the imposed drive condition.

Figure 5 shows optical micrographs of the cross sections of the recovered, incipiently, spalled samples. It is important to note that since there was only one momentum trapping ring on the entire target assembly, the regions on the outside of the samples, which are all showing higher coalescence of voids can be influenced by to late time, radial release tensile loading affects which are known for increase void linkage. Hence, we will focus on the damage in the center of the samples also marked by the blue box in Fig. 5. On a coarse scale the first apparent difference is in the thickness of the spall plane. Even though the spall planes lie in the center of the sample for all materials, the area occupied by the spall plane decreases in the order: $\mathrm{CuAg}, \mathrm{CuNb}$ and $\mathrm{Cu}$, respectively. This area directly reflects the extent of plastic deformation in each material. For example, in $\mathrm{CuNb}$, where the spall strength is the highest, most of the damage is localized to the area where the material experiences maximum tension. From Fig. 5 it is also evident that $\mathrm{Cu}$ has the least number of coalesced voids. This is consistent with a low spall strength and lower void growth rate (inferred from the rate at which the free surface velocity rises beyond the minima). In this case, void nucleation is dominant over void growth. Whereas in the case of $\mathrm{CuAg}$, whose spall strength is $6 \%$ higher than $\mathrm{Cu}$, larger areas of coalesced voids are observed. This could be due to the higher rate of free surface velocity rise and also due to the fact that the effective grain size is much smaller in this material (eutectic microstructure) which 


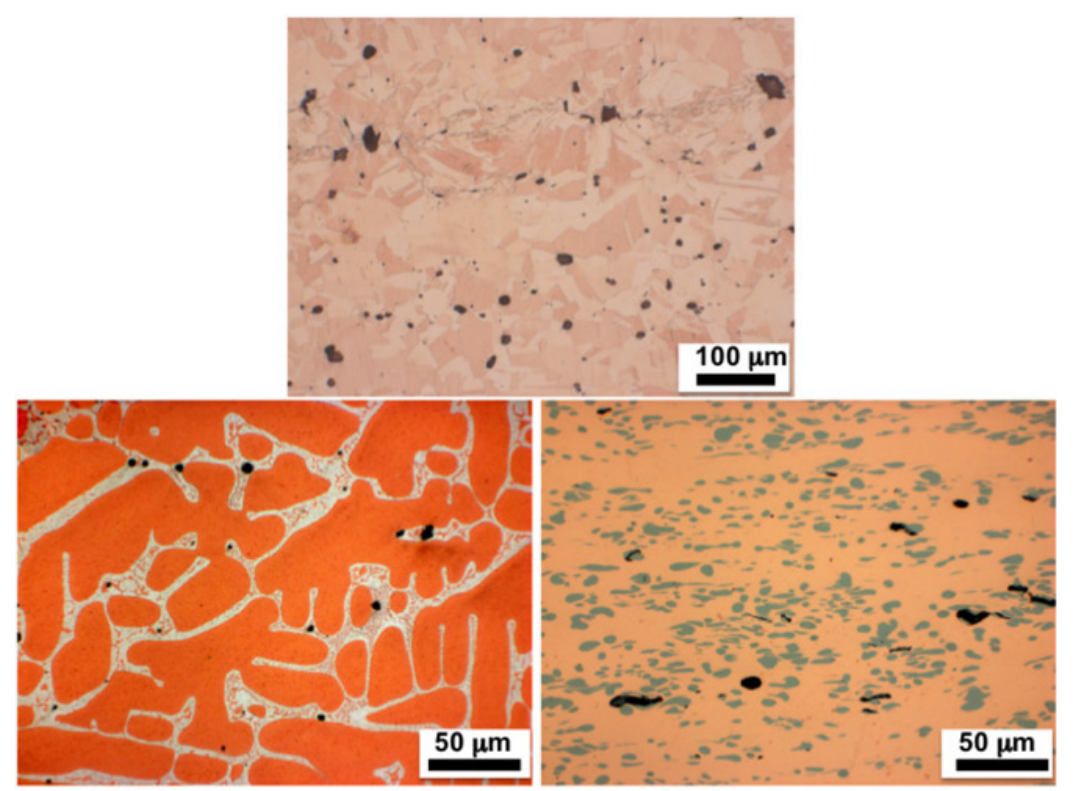

Figure 6. (Top) optical image for spalled $\mathrm{Cu}$ with black regions representing void. (Bottom right) optical image of spalled $\mathrm{CuAg}$ where white regions represent silver and black regions are voids. (Bottom left) optical image of spalled $\mathrm{CuNb}$ where the grey particles are $\mathrm{Nb}$ and the black areas are voids.

makes it easier for the voids to coalesce. In $\mathrm{CuNb}$, there is a larger number of coalesced voids in comparison to $\mathrm{Cu}$ but a lower number of coalesced voids in comparison to $\mathrm{CuAg}$. This could be because even though it is much harder to nucleate voids in this material (highest spall strength) the rate of growth of these voids is the highest (highest slope for FSV rise) once damage is formed. However, since the microstructures are not exactly the same, other factors like texture and grain size could also be influencing these results.

Figure 6 shows higher magnification optical images of the spalled $\mathrm{Cu}, \mathrm{CuAg}$ and $\mathrm{CuNb}$. These images show that in $\mathrm{Cu}$ voids tend to nucleate at grain boundaries as previously observed [9] whereas in $\mathrm{CuAg}$ voids nucleate in $\mathrm{Ag}$ and in $\mathrm{CuNb}$ voids tend to be located on the $\mathrm{Cu}$ side of the $\mathrm{Cu} / \mathrm{Nb}$ interface. Although, the majority of the voids in $\mathrm{CuNb}$ were too well developed to unambiguously determine their exact nucleation location. Despite the different microstructures, the phenomenological observations regarding the location for void nucleation appear reasonable.

\section{Conclusions}

In this research, we present the spallation response of three different materials: 1) $\mathrm{Cu}, 2) \mathrm{Cu}-10 \% \mathrm{Ag}$, and 3) $\mathrm{Cu}-$ $15 \% \mathrm{Nb}$ to investigate the influence of bi-metal interfaces on void nucleation and evolution. These materials were chosen due to the differences in crystallographic structure (FCC/FCC vs. FCC/BCC) and strength of the individual parent phases. Preliminary results indicate that the spall strength of $\mathrm{Cu}$ increases with the addition of $\mathrm{Ag}$ and $\mathrm{Nb}$ by $6 \%$ and $26 \%$, respectively. This increase was attributed to the smaller effective grain size and precipitate hardening in $\mathrm{CuAg}$ and $\mathrm{CuNb}$, respectively. The spall strength along with the void growth rates (inferred from the rise in the FSV) were also used to determine that void nucleation was the dominant process for stress dissipation in $\mathrm{Cu}$ (lowest spall strength) whereas void growth was more dominant in $\mathrm{CuNb}$ (highest spall strength). In contrast, in $\mathrm{CuAg}$, which has a slightly, higher spall strength and void growth rate than $\mathrm{Cu}$, the small effective grain size of the microstructure dominated its spallation response. Most importantly the location for the void nucleation was observed to vary with material. In $\mathrm{Cu}$, voids were observed to nucleate at grain boundaries, whereas in $\mathrm{CuAg}$ and $\mathrm{CuNb}$ voids nucleated in $\mathrm{Ag}$ (the softer phase) and on the $\mathrm{Cu}$ size of the $\mathrm{Cu} / \mathrm{Nb}$ interface. As such, this work demonstrates that there are cases where bi-metal interfaces (Like in $\mathrm{CuAg}$ ) do not control void nucleation in contrast to cases where interfaces can be important as shown in $\mathrm{CuNb}$. In our future work, we plan to quantify the mechanisms that control void nucleation and growth in these materials using molecular dynamic simulations.

Los Alamos National Laboratory is operated by Los Alamos National Security, LLC, for the National Nuclear Security Administration of the U.S. Department of Energy under contract DE-AC52-06NA25396. This work was partially sponsored by the Joint DoD/DOE Munitions Technology Development Program.

\section{References}

[1] L. Seaman, D.R. Curran and D.A. Shockley, Phys. Today 30, 46-55 (1977)

[2] L. Seaman, D.R. Curran and D.A. Shockley, J. Appl. Phys. 47, 1414-26 (1976)

[3] M.A. Meyers and C. T. Aimone, Prog. Mater. Sci. 28, 1-96 (1983) 
[4] D.R. Curran, L. Seaman and D.A. Shockley, Phys. Reports 147, 253-388 (1987)

[5] R.W. Minich, J. Cazamias, M. Kumar and A. Schwartz, Metall. Mater. Trans. A 35, 2663-73 (2004)

[6] R.W. Minich, M. Kumar, A. Schwartz and J. Cazamias, AIP Conf. Proc. 845, 642-45 (2006)

[7] G.T. Gray III, Ann. Rev. Mater. Res. 42, 285-303 (2012)

[8] G.I. Kanel, S.V. Rasorenov and V.E. Fortov, Shock Wave and High-Strain-Rate Phenomena in Materials(Marcel Dekker, New York, NY 1992)

[9] J.P. Escobedo, D. Dennis-Kolle, E.K. Cerreta, B.M. Patterson, C.A. Bronkhorst, B.L. Hansen, D. Tonks and R.A. Lebensohn, J. Appl. Phys. 110, 033513 (2011)

[10] L. Wayne, K. Krishnan, S. DiGiacomo, N. Kovvali, P. Peralta, S.N. Luo, S. Greenfield, D. Byler, D. Paisley, K.J. McClellan, A. Koskelo and R. Dickerson, Scripta Mater. 63, 1065-68 (2010)
[11] S. Christy, H.R. Pak and M.A. Meyers, Metallurgical Applications of Shock-Wave and High-Strain-Rate Phenomena (Marcel Dekker, New York, NY, 1986) 835

[12] R.S. Hixson, J.N. Johnson, G.T, Gray III and J.D. Price, AIP Conf. Proc. 370, 555-8 (1996)

[13] G.T. Gray III, ASM International 8, 530 (2000)

[14] O.T. Strand, D.R. Goosman, C. Martinez, T.L. Whitworth, W.W. Kuhlow, Rev. Sci. Instrum. 77, 083108 (2006)

[15] B.J. Jensen, D.B. Holtkamp, P.A. Rigg, D.H. Dolan, J. Appl. Phys. 101, 013523 (2007)

[16] S.P. Marsh, LASL Shock Hugoniot Data (University of California Press, 1980)

[17] S.A. Novikov, I.I. Divnov. and A.G. Ivanov, Phys. Met. Metallogr. 21, 122 (1966)

[18] G.I. Kanel, J. Appl. Mech. Tech. Phys. 42, 358 (2001)

[19] J.P. Escobedo, E.N. Brown, C.P. Trujillo, E.K. Cerreta and G.T. Gray III, J. Appl. Phys. 113 (2013)

[20] E.B. Zaretsky and G.I. Kanel, J. Appl. Phys. 110, 073502 (2011) 